\title{
La violencia doméstica en el Egipto antiguo
}

José Miguel PARRA ORTIZ

Los relatos mitológicos, los textos literarios, los documentos legales y algunos estudios paleopatológicos demuestran que la violencia doméstica fue una constante de la vida en el Egipto antiguo. A pesar de que gozaba de igualdad legal con respecto al hombre y de que en los textos literarios siempre aparece como la generadora de la violencia doméstica, en realidad fue la mujer quien la sufrió con mayor asiduidad, como nos muestra la documentación existente.

\section{Domestic violence in the Ancient Egypt}

Mythological narratives, literary texts, legal documents, forensic testimonies and some paleopathological studies prove that gender violence was a constant in ancient Egyptian daily life. However, despite the fact that Egyptian women had legal equality with men and despite evidence in literary texts, where women always appears as the instigators of domestic gender violence, Egyptian women suffered that violence with more regularity than men, as proved by documentary evidence.

KEY WORDS: women, gender violence, literature

$\mathrm{A}$ tendiendo a la relevancia social que parece haber adquirido en los últimos tiempos la violencia doméstica ${ }^{1}$, resulta adecuado estudiar si ésta existió en el Egipto antiguo y, de ser así, bajo qué formas se manifestó.

Según la reciente legislación española, la violencia doméstica queda definida como sigue: "3. La violencia de género a que se refiere la presente Ley comprende todo acto de violencia física y psicológica, incluidas las agresiones a la libertad sexual, las amenazas, las coacciones o la privación arbitraria de libertad"2. No obstante, la ley española sólo ampara a las mujeres: "1. La presente Ley tiene por objeto actuar contra la violencia que, como manifestación de la discriminación, la situación de desigualdad y las relaciones de poder de los hombres sobre las mujeres, se ejerce sobre éstas por parte de quienes sean o hayan sido sus cónyuges o de quienes estén o hayan estado ligados a ellas por relaciones similares de afectividad, aun sin convivencia"3, pero en el presente artículo estudiaremos la

1. Respondiendo a una petición del Gobierno, la Real Academia Española de la Lengua propuso como ajustadas a la semántica y la gramática del castellano las expresiones: "violencia de sexo", "violencia contra las mujeres" y "violencia doméstica" como traducciones de la expresión inglesa gender violence y no "violencia de género", que no es sino un calco de la frase original en el cual no se tiene en cuenta que, en español, sólo los elementos gramaticales tienen "género", el resto (animales, personas y cosas) tienen "sexo". En este artículo se utilizarán las expresiones propuestas por la RAE.

2. Ley Orgánica $1 / 2004$, de 28 de diciembre, de Medidas de Protección Integral contra la Violencia de Género. Título Preliminar. Artículo 1. Objeto de la Ley.

Fecha de recepción: 10 de enero de 2007

Fecha de aceptación: 25 de junio de 2007 
violencia doméstica generada en el Egipto antiguo, tanto por hombres como por mujeres ${ }^{4}$; ofreciendo una lista de ejemplos que, si bien no es exhaustiva, esperamos que al menos sea bastante completa.

\section{LA VIOLENCIA DOMÉSTICA MITOLÓGICA}

El primer ámbito en el que investigaremos la presencia de violencia doméstica es en el de la mitología, pues en el Egipto antiguo el mundo de lo divino sirve muchas veces como referencia de actitudes humanas. Esta relación es la que permite explicar, por ejemplo, la técnica básica de la magia egipcia: la "transferencia", consistente en identificar una situación concreta del ámbito de los seres humanos con una situación concreta ocurrida en el mundo de los dioses; es decir, en "transferir" una vivencia de la vida diaria a la esfera de los seres divinos 5 . Por lo tanto, la presencia en el mundo mitológico de violencia doméstica será un indicio de su existencia en la vida de los habitantes del valle del Nilo. Esta violencia, tanto la mitológica como la literaria (objeto del próximo apartado), serán consideradas prima facie. Sólo nos interesa su manifestación como acto en sí mismo, sin pretender indagar en los motivos de su presencia en el texto; es decir, el subtexto o motivo subyacente a su inclusión en el mismo, que en muchas ocasiones puede tener la intención de utilizar esos actos virulentos para transmitir un mensaje por completo diferente ${ }^{6}$.

\section{Violencia física}

La violencia doméstica es notoria en el más conocido de los relatos mitológicos egipcios, el de Isis y Osiris. El hecho que origina toda la narración es el asesinato, con alevosía y premeditación, de Osiris a manos de su hermano Seth ${ }^{7}$ :

Seth vino apresurado y llegó contra Osiris en Nedyt de Hadjefau bajo un árbol llamado aru en el primer mes de la inundación, día 17, cometió un acto de gran violencia contra él y lo hundió en las aguas ${ }^{8}$.

En cambio, en la narración de Horus y Seth en vez de cólera fraterna nos encontramos con actos violentos de una madre contra su hijo:

Entonces Horus fue a contárselo a su madre Isis: "Mira, Isis, madre, ven y mira lo que me ha hecho Seth". Abrió su mano y le dejó ver el semen de Seth. Ella gritó, cogió su cuchillo, le cortó la mano y la lanzó al agua. Entonces hizo una nueva mano para él ${ }^{9}$.

Y de este mismo hijo contra su madre:

Entonces Horus, hijo de Isis, se enfadó con su madre Isis. Salió con la cara feroz como la de un leopardo y con su cuchillo de 16 deben en la

3. Véase la nota 2.

4. En realidad deberíamos incluir también los actos violentos contra los menores en el ámbito doméstico; pues, atendiendo al estudio de los cementerios de Deir el-Medina, eran socializados desde pequeños y, por lo tanto, eran seres sociales a los que había que tener en cuenta (Meskell, 1999: 130, 169, 173, 214). No obstante, si las pruebas de violencia doméstica entre adultos no son muy abundantes, en el caso de los niños son prácticamente inexistentes. Pese a ello, atendiendo a las técnicas pedagógicas preconizadas en algunos textos, hemos de darla más que por supuesta: "No pases el día haraganeando o te golpearán; la oreja de un muchacho se encuentra de hecho en su espalda y escucha cuando se la golpea" (Papiro Anastasi III, 3/10-4/4; Williams, 1972: 218); "Me convertí en un joven a tu lado. Golpeaste mi espalda; tus enseñanzas entraron en mi oreja" (Papiro Lansing BM 9994; Lichtheim, 1976: 172). Sobre la infancia y los niños en general véanse: Janssen y Janssen, 1990; Parra Ortiz, 2003: 331-353; y Parra Ortiz, 2006: 150.

5. Koenig, 1994: 57-58.

6. Véanse las notas 12 y 18.

7. Al menos tal y como nos la cuenta Plutarco en Sobre Isis y Osiris. Sobre Osiris ver Griffiths, 1980.

8. Ritual para "el final de las operaciones de momificación” (Quirke, 1992: 54).

9. Papiro Chester Beatty I (Lichtheim, 1976: 219-220).

10. Papiro Chester Beatty I (Lichtheim, 1976: 219). 
mano. Cortó la cabeza de su madre Isis, la cogió en sus brazos y subió a la montaña ${ }^{10}$.

Violencia doméstica, asimismo (en este caso de una nieta contra su abuelo), sería la de la diosa Isis, quien para conseguir sus fines y averiguar el nombre secreto de Ra, no dudó en utilizar una serpiente para envenenar a su pariente; un flagrante caso de violencia contra los mayores:

Él escupió su saliva hacia la tierra. Isis la trituró en sus manos con la tierra en que estaba, elaboró una noble serpiente, y la modeló con la forma de las agujas, pero no se deslizaba hacia delante. Y ella la arrojó junto al camino (?) que el gran dios solía recorrer, de acuerdo con el deseo de su corazón, a través del Doble País.

El dios augusto apareció al exterior y los dioses de palacio estaban tras él. Fue a pasearse como solía hacer cada día. La serpiente augusta le mordió, el fuego augusto salió por sí mismo (?) y ella desapareció entre la vegetación (?) ${ }^{11}$.

\section{Violencia sexual}

Los ataques sexuales también tienen cabida en este mundo de dioses, y no precisamente entre desconocidos, sino entre miembros de la misma familia; como este acto de incesto forzado de un hijo contra su madre ${ }^{12}$ :

He aquí que Gueb vio a su madre, que le amaba mucho. Su corazón [el de Gueb] se despreocupaba de ella. La tierra (...) por ella con gran aflicción.
La Majestad de Shu voló hacia el cielo con sus compañeros. Tefnut se quedó en el lugar de su coronación en Menfis. Ella fue hacia la residencia real de Shu al mediodía. [...] Entonces, la Majestad de (...). Hete aquí que él la encontró en ese lugar llamado Pi-Kharoti y hete aquí que se apoderó de ella de viva fuerza. Fue una gran revolución en la residencia (...)

La Majestad de Gueb apareció coronada sobre el trono de su padre Shu, y todos los habitantes de la residencia besaron la tierra delante de él ${ }^{13}$.

También conocemos el caso de la violación de una mujer por parte del que, en otros textos, aparece mencionado como su esposo. Se trata de Seth y la diosa asiática Anat ${ }^{14}$, cuyas vestimentas eran de hombre y se comportaba como tal, si bien sus formas quedaban marcadas como las de la mujer que era ${ }^{15}$. Al verla en el agua, Seth no pudo refrenarse y allí la asaltó, actuando literalmente como un animal ${ }^{16}$. Dados sus rasgos guerreros, la diosa se defendió con ahínco, pese a lo cual terminó siendo desflorada con un cincel y violada con fuego; pero su esposo no quedó incólume, resultando herido en la frente y en el ojo ${ }^{17}$.

Asimismo protagonizado por el dios Seth, tenemos un caso de violación homosexual contra su sobrino Horus ${ }^{18}$ :

Seth le dijo a Horus: "Ven y pasemos un día de fiesta en mi casa". Horus respondió: "Lo haré, lo haré". Cuando llegó la tarde, el lecho estaba dispuesto para ellos y se acostaron. Durante la noche,

11. La leyenda de Isis y Ra (López, 2005: 112-113).

12. Identificado, más allá del atentado contra la libertad sexual, como una violenta toma de poder (Meeks; Favard-Meeks, 1995: 93).

13. Naos 2248 de Ismailia (Goyon, 1936: 31-32).

14. Papiro Chester Beatty VII, verso 1, 5 y ss. (Gardiner, 1935: 62 y ss.).

15. Te Velde, 1977: 56.

16. El verbo empleado en el texto no es $n k$, que aparece siempre al referirse al acto sexual en el que intervienen personas, incluso cuando su compañero de juegos es un animal, sino el que se utiliza para referirse al ayuntamiento entre dos animales (Dawson, 1936: 107).

17. Te Velde, 1977: 56 y 37.

18. En este caso, el subtexto de la acción queda definido como un intento por parte de Seth de marcar ignominiosamente a su sobrino e impedirle acceder al trono de Egipto (Parkinson, 1995: 65-66; Parra Ortiz, 2006: 153-154, 159-180). 
Seth hizo que su miembro se pusiera duro y lo introdujo entre los muslos de Horus ${ }^{19}$.

\section{VIOLENCIA DOMÉSTICA LITERARIA}

Como "parte integral que son de las redes de significado que llamados cultura" 20 , los textos literarios son un reflejo (por distorsionado o intencionado que sea) de la sociedad que los produjo; por lo tanto, la presencia en ellos de relatos violentos será un indicio de su existencia en la vida real ${ }^{21}$.

\section{Violencia física}

Uno de los más interesantes y conocidos cuentos de la literatura egipcia, Los dos hermanos, contiene un sinnúmero de escenas de violencia; hasta el punto de que ésta forma la base del relato. La primera de ellas es un intento de fratricidio:

Entonces el hermano mayor se puso como un leopardo del sur, agarró su lanza y la cogió en su mano. El (hermano) mayor esperó detrás de la puerta de su establo para matar a su hermano menor cuando viniera al anochecer para hacer entrar las bestias en el establo ${ }^{22}$.

La segunda parte del relato nos narra los tres asesinatos sufridos por el desgraciado protagonista de la historia, Bata, encargados por su esposa: el primero, cuando ordena a los soldados del faraón que han ido a llevarla a la Residencia que corten el pino donde él había dejado su corazón; el segundo, cuando convence al faraón con sus armas de mujer de que sacrifique el hermoso toro en el que se había convertido Bata; y el tercero, cuando consigue de nuevo que su majestad mate a Bata, esta vez al talar la persea en la que se había transformado. La violencia final la ejercerá Bata contra su esposa (a su vez su madre, pues le había dado a luz tras quedarse embarazada al tragarse una astilla del árbol), al juzgarla y condenarla a muerte.

La desgraciada criada que aparece en la escena final del Papiro Westcar también es objeto de malos tratos, primero a manos de su señora:

Pasaron los días y Reddjedet riñó a la sirvienta e hizo que se la castigara con golpes. Entonces la sirvienta dijo a las gentes que estaban en la casa: “¿Puede ella hacer esto contra mí?”’33.

Y después en las de su hermano, por el mero hecho de quejarse ante él del injusto castigo que le había aplicado su señora:

Él inclinó la cabeza y dijo: "Señora mía, mira, ella vino a explicarme [lo ocurrido (?)] y se detuvo un momento junto a mí. Entonces yo le di un mal golpe, ella fue a coger un poco de agua y el cocodrilo la atrapó” 24 .

\section{Amenazas de violencia}

La violencia no se caracteriza exclusivamente por la aplicación de dolor físico, también puede ser ejercida mediante la presión psicológica, las meras amenazas o los intentos de ejercerla, por más que no culminados. Es el caso del padre de la princesa de El príncipe predestinado, que mandó asesinar al advenedizo que había ganado en buena lid la mano de su hija y hubo de renun-

19. Papiro Chester Beatty I (Lichtheim, 1976: 219-220).

20. Parkinson, 2002: 86.

21. Algunos autores se manifiestan contrarios a considerar los textos literarios como una fuente de información directa de la sociedad del Reino Nuevo, refiriéndose en concreto a los poemas amorosos (Mathieu, 1993: 3).

22. López, 2005: 125-136.

23. Los cuentos del papiro Westcar (López, 2005: 98).

24. López, 2005: 98. 
ciar a ello ante la decisión de ésta de matarse si

le pasaba algo a su enamorado:

Entonces el mensajero fue y repitió a su padre todo lo que ella había dicho y su < padre> ordenó que fueran gentes para matarlo allí donde estaba. Pero la joven $<$ les $>$ dijo: "Tan cierto como perdura Ra, que si se le mata, cuando se ponga el sol, yo estaré muerta. No pasaré una hora estando viva más tarde que él’"25.

\section{Violencia legal}

Bajo esta definición podemos incluir a la violencia doméstica no ejercida directamente, sino por intermedio de los mecanismos judiciales del Estado, engañados por los subterfugios de una de las partes en litigio. Un caso lo tenemos de nuevo en Los dos hermanos, cuando la cuñada de Bata intenta convencer a su esposo de que ha sido violada, para que él, en su justo derecho, ejecute la pena capital contra su hermano ${ }^{26}$ :

Ahora bien, la mujer del hermano mayor tenía miedo de las palabras que había dicho. Trajo grasa y sebo y se aderezó como si hubiera sido golpeada, fingiendo y con la intención de decir a su marido: “ Es tu hermano quien me ha golpeado!”27.

Una intención semejante fue la de Mentira para deshacerse de su hermano, a quien acusó en falso ante el tribunal, para luego exigir de éste un castigo ejemplar:

Entonces Mentira dijo a la Enéada: "Disponed que Verdad sea conducido (aquí), que se le ciegue de sus dos ojos y que se le haga guardián de la puerta de mi casa". La Enéada hizo todo lo que él había dicho ${ }^{28}$.

\section{Casos atestiguados de violencia doméstica}

Los ejemplos incontrovertibles de violencia doméstica que poseemos son bien escasos, pero no por ello inexistentes. Los más llamativos son las diferentes conspiraciones organizadas en el harén por parte de una de las reinas para colocar en el trono de Egipto a su propio hijo a costa de la muerte de su propio esposo, el soberano. Estas conjuras parecen haber existido desde al menos finales de la V Dinastía.

\section{Conspiración para asesinar}

Una posible conspiración podría haber afectado a Teti. Mencionada por Manetón: "Othoes, durante 30 años: fue asesinado por su guardia personal" ${ }^{29}$, parece posible encontrar indicios de la misma en los cementerios de Sakkara ${ }^{30}$. La segunda conjura de la que tenemos noticia es el intento de derrocamiento de Pepy I que narra Weni en su tumba:

Hubo un proceso legal en secreto en el harén real contra la esposa real, la "grande de afecto", su majestad me hizo escucharlo yo solo ${ }^{31}$.

Ya en el Reino Medio, el fundador de la XII Dinastía fue muerto a manos de su propia guardia, instigada por una de sus esposas ${ }^{32}$. Del Reino

25. Los dos hermanos (López, 2005: 121).

26. La impresión que nos proporcionan la mayoría de las fuentes egipcias es que el adulterio descubierto in fraganti podía terminar con el asesinato del seductor por parte del marido engañado o de su entorno; pero seguramente se trate de una exageración teórica (Eyre, 1984: 102, 98). Véase también la nota 52.

27. Los dos hermanos (López, 2005: 129).

28. La disputa de Verdad y Mentira (López, 2005: 156).

29. Manetón, 1940: 53.

30. Como sugiere el estudio de Kanawati, 2003.

31. Strudwick, 2005: 353. Sobre el redescubrimiento de la mastaba de este personaje y los nuevo datos que completan su biografía véase Richard, 2002.

32. Las enseñanzas del rey Amenemhat I (Simpson, 2003: 168-169). 
Nuevo conocemos la gran conspiración contra Ramsés III ${ }^{33}$, destinada a poner en el trono al hijo de una de sus esposas secundarias.

\section{Acoso sexual}

Habida cuenta de la familia extensa que se formaba en la casa de un personaje pudiente, no es extraño que las relaciones de poder creadas entre sus habitantes generaran casos de violencia doméstica ${ }^{34}$. En el enrarecido ambiente de la residencia de Heqanakhte, la presión psicológica ejercida de forma epistolar por el padre sobre su hijo mayor encuentra su paralelo en la que sufre la nueva esposa de aquél; hasta el punto de verse acosada sexualmente por alguno de los trabajadores $^{35}$ :

Como ese hombre vive para mí - me estoy refiriendo a Ip - quien quiera que haga un avance sexual contra mi nueva esposa, está en contra de mí y yo en contra de él. Como ésta es mi nueva esposa, y ya se sabe cómo debe ser ayudada la nueva esposa de un hombre, cualquiera que pueda ayudarla es como si me ayudara a $\mathrm{mi}^{36}$.

\section{Violencia sexual}

En algunos casos, sabemos que el acoso terminó transformándose en ataques sexuales. El primero del que tenemos noticias tiene como protagonista a Paneb, el matón de Deir el-Medina ${ }^{37}$ :

[Memorandum] relativo al hecho de que despojó a Iyem de sus vestidos y la tumbó sobre el

[ 144 ] remate de un muro y la forzó ${ }^{38}$.
No es el único caso conocido de violación; sabemos de otro que tiene como protagonistas a dos varones, en lo que quizá sea un remedo de las intenciones de Seth para con Horus ${ }^{39}$ :

Cargo relativo a la violación realizada por este marinero Panakhtta [contra] un trabajador del campo de la heredad de Khnum, señor de Elefantina ${ }^{40}$.

\section{Violencia psicológica}

No cabe duda de que si una persona carece de medios propios, expulsarla de su hogar es ejercer la violencia contra ella; en este caso, quizá de forma psicológica, para hacerle comprender su dependencia. En Deir el-Medina sabemos de un hombre que maltrató así a su esposa, expulsándola repetidas veces del hogar conyugal y dejándola expuesta a la caridad de otros:

Su mujer pasó cuarenta días viviendo conmigo en mi casa, y la alimenté, dándole un saco de cebada y diez panes. Y él la expulsó otra vez, y ella pasó veinte días en la casa de Menna, al que di alimentos [sigue una lista ${ }^{41}$.

\section{Violencia física}

En algunas ocasiones, la mera presión psicológica degeneró en violencia física. Conocemos un caso sucedido en Elefantina y protagonizado por el sacerdote Penanuqet contra una posible antigua amante y la hija de ésta:

Memorandum relativo al hecho de que el hombre prendió fuego a la casa de la sirvienta [...] Mutneferet. [Ella fue] a decírselo. Él la dejó ciega y dejó

33. Vernus, 1992: 141-157; Grandet, 1993: passim; Redford, 2002.

34. Ya hemos visto uno de estos casos en la literatura (los últimos párrafos conservados del Papiro Westcar).

35. También podría tratarse de un nuevo ejemplo de falsa acusación para deshacerse de alguien que la molestaba.

36. Los papiros de Heqanakhte (Wente, 1990: 62; Allen, 2002: 17).

37. Sobre este personaje véanse: Bierbrier, 1978: 138-139; Bierbrier, 2000: 51-54.

38. Papiro Salt 124, recto 1, 29 (Vernus, 1993: 110).

39. Véase la nota 18.

40. Papiro judicial de Turín, verso 3.4-5 (Gardiner, 1948: 81.16-82.1).

41. McDowell, 1999: 34. 
ciega también a Baksetshyt, su hija. Hoy día todavía están ciegas $^{42}$.

Siendo Egipto el reino de la maat, no es de extrañar que las personas atacadas recurrieran a la justicia ordinaria en busca de una reparación. En ocasiones es el hombre el objeto de la violencia gratuita:

En cuanto a mí, soy un servidor de Amen-em-one, un miembro del equipo. Llevé el serón a la casa de Pa-yom y convertí a su hija en mi esposa. Después de pasar la noche en casa de mi padre, salí para ir a su casa y encontré al trabajador Mery-Sekhmet, hijo de Mena, durmiendo con mi esposa en el cuarto mes del verano, día 5. Salí y se lo dije a los oficiales, pero los oficiales me dieron 100 golpes de bastón, diciendo: “¿De verdad? ¡Qué dices!”. Entonces el jefe de los trabajadores In-her-khau dijo: “¿Qué significa eso de dar 100 bastonazos al que llevó el serón, mientras era otro el que fornicaba? Lo que han hecho los oficiales es un gran crimen"43.

También las mujeres maltratadas recurrían a la justicia ordinaria. Por desgracia, desconocemos el porcentaje de ellas que lo hacía; de hecho, el caso que presentamos como ejemplo bien puede ser algo excepcional, debido a las condiciones particulares que se daban en Deir el-Medina, de donde proviene:

Año 20, tercer mes del verano, día 1. Día que el trabajador Amen-em-ope compareció ante el tribunal (formado por) [siguen siete nombres] [laguna en el texto] diciendo, "En cuanto a mí, mi marido [laguna en el texto]. Entonces me pegó, me pegó [laguna en el texto]. E hice que trajeran a su madre, él [laguna]".

Se encontró que no tenía razón, y uno hizo [laguna en el texto] y le dije, "Si tu [laguna en el texto] delante de los magistrados".

Y realizó [un juramento delante del señor] diciendo, "Igual que Amón vive [laguna en el texto] ${ }^{44}$.

\section{Paleopatología de la Violencia física}

El único caso incuestionable de violencia física que por ahora se conoce para el Egipto antiguo es el esqueleto de un mujer fallecida entre 30 y 35 años de edad, hallado en un cementerio del Reino Medio en Abidos. Su estudio ha revelado una vida de continuos malos tratos ${ }^{45}$. Las costillas presentan roturas en ambos lados de la caja torácica, mientras que la mano izquierda se rompió por el segundo metacarpo y la muñeca izquierda sufrió una fractura múltiple en los extremos distales del radio y el cúbito, que además tuvo la desdicha de infectarse. Las heridas de la caja torácica sugieren que la mujer fue golpeada por alguien que utilizó ambos puños. La rotura del metacarpo parece indicar una herida de tipo defensivo, resultado de poner el canto de la mano para evitar ser golpeada por algún objeto contundente. El radio y el cúbito fracturados en su extremo distal son otra lesión defensiva típica, ocurrida casi siempre cuando alguien extiende los brazos hacia delante para detener una caída. Las heridas parecen haber tenido lugar en momentos distintos y lo bastante alejados entre sí como para poder sanar, por lo que podría tratarse de una persona propensa a los accidentes. Sin embargo, la otra lesión visible en el cuerpo invalida por completo esta posibilidad. La parte interior de la quinta y la sexta costillas izquierdas presenta una fisura en el extremo cercano al esternón. Se trata de una herida longitudinal, realizada con seguridad por la hoja de un objeto cortante. Su presencia en el interior de las costillas indica que el arma penetró por la espalda de la víctima, cerca de la columna vertebral, fracasando en su intento de atravesarla de parte a parte al ver detenido su avance por las costillas. Fue el triste final de una vida de continuos abusos ${ }^{46}$.

42. Papiro de Turín 1887, recto 2, 10-11 (Vernus, 1993: 126).

43. Papiro de Deir el-Medina 27 (McDowell, 1999: 47-49).

44. Ostracon Nash 5r (Allam, 1973: 221-222; McDowell, 1999: 34).

45. El esqueleto está sin publicar, pero aparece un resumen de las lesiones en: Baker, 1997: 106-116. 


\section{Conclusiones}

Como hemos podido ver, a pesar de la imagen de idílico paraíso agrícola que en ocasiones se ha dado de la sociedad faraónica ${ }^{47}$, lo cierto es que la violencia doméstica fue una constante de la vida familiar en el Egipto antiguo. La encontramos en documentos de todo tipo: literarios, administrativos, judiciales e incluso forenses, lo cual nos indica que fue una realidad social irrebatible. Por este mismo motivo se tomaron medidas para intentar atajarla.

La misma literatura que la explicita y utiliza como ejemplo, intenta detener la violencia doméstica mediante los textos sapienciales, como en Las máximas de Ptahhotep: "No seas brutal, el tacto consigue más cosas de tu mujer que la violencia"48 o en Las Máximas de Ani: "No controles a tu esposa en su casa, cuando sabes que es eficiente; no le digas: ¿¿Dónde está esto? ¡Tráelo!' cuando lo tenía en su lugar correcto" ${ }^{49}$. Con este tipo de admoniciones se intenta inculcar a los miembros de la elite lectora y a sus oyentes, cuál es el comportamiento adecuado para con los más débiles. El modelo a seguir era conocido por todos, como podemos leer en El campesino elocuente, cuando el habitante del oasis destaca las virtudes de quien le escucha con la esperanza de recibir justicia de él:
Pues eres un padre para el huérfano, Un marido para la viuda, Un hermano para la divorciada ${ }^{50}$.

Este comportamiento, que se desea intrínseco a la condición social elevada, teóricamente a copiar por el resto de los súbditos del faraón, se expone públicamente desde las paredes de las tumbas e hipogeos: "No hay una sola hija de ciudadano a la que haya avergonzado, ni viuda a la que haya oprimido" ${ }^{51}$. A fin de cuentas, al menos en teoría, el Estado es el único con potestad para ejercer la violencia ${ }^{52}$. El monarca es el encargado de que reine maat y las personas que soportan actos de violencia han de acudir a él por intermedio de sus tribunales en busca de reparación, cosa que como hemos visto hacían tanto hombres como mujeres. No parece que en todas las épocas fuera posible contar con la salvaguardia del soberano y si Ramsés III alardea de que: "Yo hice posible que la mujer de Egipto siguiera su camino, que se hizo más sencillo, hacia donde ella quería, sin que ninguna persona la asaltase en ruta" ${ }^{53}$, seguramente sea porque lo contrario era lo habitual. Si ello es así, podríamos entonces tener una explicación para el hecho de que, en ocasiones, el faraón pise, domine y controle a su pueblo con los mismos métodos ideológicos e iconográficos destinados a los enemigos de Egipto. Es la imagen del pájaro rekhyt a los

46. Por supuesto, caben otras explicaciones para el conjunto de lesiones descritas, pero ésta es la más sencilla y menos rocambolesca.

47. El mejor ejemplo de ello quizá sea: Montet, 1946.

48. Laffont, 1998: 46.

49. Lichtheim, 1976: 143.

50. Parkinson, 1998: 61.

51. Tumba de Amenemhat, Beni Hassan (Lichtheim, 1992: 139).

52. Y aún así, con reticencias en cuanto a la pena capital, como vemos en el Papiro judicial de Turín, cuando Ramsés III se lava las manos diciendo que encomendó a sus investigadores que no cometieran errores a la hora de encontrar a los culpables de su intento de asesinato: "Se pusieron en marcha, los interrogaron, hicieron que aquellos muriesen por sus propias manos, sin que yo tuviera que saberlo. Infligieron un castigo a los demás, sin que yo tuviera que saberlo tampoco y esto después de que [yo les diera las instrucciones] siguientes: 'Sed honrados y cuidaos de que [alguien] no sufra equivocadamente un castigo [infligido por un magistrado] que no conozca su caso', así dije de continuo" (Papiro judicial de Turín, 2, 2-3, 5 [Vernus, 1993: 143]). 
pies del soberano, quien de este modo identifica a los habitantes del valle del Nilo como sus enemigos, generadores de caos, y pone el remedio para controlarlos.

La falta de eficacia contra la violencia doméstica por parte del faraón hizo que sus súbditos procuraran lograrla por otros medios. Son padres que, preocupados por el destino de sus hijas una vez abandonaban el hogar familiar para irse a vivir con sus esposos, hacían firmar a sus yernos "contratos prematrimoniales", poniendo la venda antes que la herida:

Juramento ante el señor, v.s.f., que pronuncia: “Al igual que Amón permanece, igual que el monarca permanece, si incumplo mi palabra y abandono a la hija de Tener-Montu en el futuro, recibiré 100 golpes y seré desprovisto de todas las propiedades que adquiera con ella". [Sigue la firma de los testigos y los dos implicados $]^{54}$.

Algo similar sucede cuando otro padre, por escrito, asegura a su hija que sería acogida de nuevo si las cosas salieran mal en su matrimonio:

El trabajador Hor-em-wia dice a la señora Tenet-djeseret, su hija: "Eres mi buena hija. Si el trabajador Baki te expulsa de su casa, actuaré. La casa [¿pertenece al?] faraón, v.s.f; pero puedes vivir en el pórtico de mi almacén, porque fui yo quien lo construyó, y nadie en esta tierra te expulsará de all'’"55.

Aparte de esta constatación de la existencia de la violencia doméstica, si nos fijamos en la documentación reunida, vemos que los actores de la misma varían atendiendo al medio donde aparece. En el mundo mitológico los causantes de la violencia son de ambos sexos, no hay distingos entre dioses y diosas a la hora de ejercerla o sufrirla: Seth ataca a su sobrino y a su hermano; Isis hace lo propio con su abuelo, su hermano e incluso su hijo y éste con ella. El de los dioses es un reino de igualdad total, donde ambos sexos interactúan violentamente entre ellos sin cortapisas, ni las negativas consecuencias que eso tendría en el mundo de los humanos. Esta circunstancia varía si pasamos al campo literario, donde nos encontramos con un escenario por completo distinto: aquí es la mujer la que prácticamente siempre aparece como la parte activa de la violencia, generándola contra varones y otras mujeres de forma casi indiscriminada. Los ejemplos de Reddjedet y de la esposa y la cuñada de Bata son bastante ilustrativos al respecto. Esta imagen negativa y violenta parece adecuarse a la que de ellas nos ofrecen los textos sapienciales que, si bien por un lado conminan a sus lectores a proteger a las féminas y tratarlas con respeto, por el otro las describen con características propias casi del medievo europeo: agentes de la tentación y creadoras de problemas que hay que evitar a toda costa:

Si quieres conservar una amistad

En la casa que entres,

Ya sea como señor, hermano o amigo,

¡Cuídate de acercarte a las mujeres ${ }^{56}$ !

Los hombres también generan violencia doméstica literaria, pero es contra otros hombres y nunca contra las féminas; son los casos de Mentira, el hermano mayor de Bata, o del príncipe de Retenu contra su futuro yerno. Desgraciadamente, al pasar al mundo real nos encontramos con que la imagen de la mitología y la literatura son por completo falsas. Esta otra documentación siempre nos habla de las mujeres como parte pasiva de la violencia doméstica; pese a ser legalmente iguales a los

53. Papiro Harris I, 78, 8-9 (Baines; Malek, 2002: 204).

54. Ostracon Bodleian Library 253 (Allam, 1973: 40-42; McDowell, 1999: 33).

55. Ostracon Petrie 61 (Allam, 1973: 242-243; McDowell, 1990; 123-124; McDowell, 1999: 42).

56. Instrucciones de Pthahotep (Lichtheim, 1975: 68). 
hombres y contar con la protección de la justicia del soberano. No podemos decir que las cosas hayan mejorado mucho desde entonces. Resulta triste comprobar cómo han tenido que transcurrir más de dos mil años para que las mujeres occidentales (y sólo ellas) consigan los mismos derechos que ya disfrutaban las egipcias de la época faraónica, y más triste aún darse cuenta de que, como también les sucedía a las féminas del valle del Nilo, pese a ellos continúan siendo el objeto preferente de la violencia doméstica ${ }^{57}$.

57. No obstante, conviene mostrarse cautelosos con las afirmaciones rotundas; pues como demuestran las estadísticas españolas, si el 60 por ciento de los asesinatos dentro de la pareja los cometen los hombres, eso significa que el 40 por ciento los cometen las mujeres (Díaz Herrera, 2006: 763). 


\section{Bibliografía}

Allam, S.

1973 Hieratische Ostraka und Papyri aus der Ramessidenzeit. Tübingen.

Allen, J. P.

2002 The Heqanakht papyri. New York.

Baines, J; MaleK, J.

2002 Atlas of ancient Egypt. Cairo.

BAKER, B. J.

1997 Contribution of biological Anthropology to the understanding of ancient Egyptian and Nubian societies, en Lustig, J. (ed.): Anthropolgy and Egyptology a developing dialogue, Sheffield: 106-116.

BIERBRIER, M. L.

1978 Notes on Deir el-Medina II: The career of Paneb, JSSEA 8: 138-139.

2000 Paneb rehabilited, en Demaree; R. J. y Egberts. A. (eds.): Deir el-Medina in the Third Milenium. A tribute to Jac J. Janssen, Leiden: 51-54.

BRUNNER, H.

1978 L'éducation en ancienne Égypte, en Mialaret, G. y Vial, J. (dirs.): Histoire mondiale de l'éducation, Paris: 65-86.

DAWSON, W. R.

1936 Notices of Recent Publications. Observations on Passages in Ch. Beatty Papyri VII, VIII, and XII, JEA 22: 106-108.

Díaz Herrera, J.

2006 El varón castrado. Verdades y mentiras de la violencia doméstica en España. Madrid.

Eyre, C. J.

1984 Crime and Adultery in Ancient Egypt, JEA 70: 92-105.
Gardiner, A. H.

1935 Hieratic Papyri in the British Museum.

Third Series: Chester Beatty Gift.

London.

1948 Ramesside Administrative Documents. London.

Goyon, G.

1936 Les travaux de Chou et les tribulations de Geb d'aprés le naos 2248 de Ismaïlia, Kemi 6: 1-42.

GRANDET, P.

1993 Ramsès III. Histoire d'un règne. Paris.

Griffiths, J. G.

1980 The origins of Osiris and his cult. Leiden.

JANSSEN, R. M.; JANSSEN, J. J.

1990 Growing up in ancient Egypt. London.

Kanawati, N.

2003 Conspiracies in the Egyptian palace. Unis to Pepy I. London.

KoENIG, Y.

1994 Magie et magiciens dans l'Égypte ancienne. Paris.

LAFFONT, E.

1998 Les livres des sagesses des pharaons. Paris.

Lichtheim, M.

1975 Ancient Egyptian Literature. A Book of Readings. Volume I: The Old and Middle Kingdoms. Berkeley.

1976 Ancient Egyptian Literature. A Book of Readings. Volume II: The New Kingdom. Berkeley.

1992 Maat in Egyptian autobiographies and related studies. $(O B O, 120)$. Gottingen. 
LÓPEZ, J. (ED.)

2005 Cuentos y fábulas del antiguo Egipto. Madrid.

McDowell, A. G.

1990 Jurisdiction in the Workmen's Community of Deir el-Medina. Leiden.

1999 Village life in ancient Egypt. Laundry lists and love songs. Oxford.

Mathieu, B.

1993 La poésie amoureuse de l'Égypte ancienne. Recherches sur un genre littéraire au Nouvel Empire. (BdE, 106). Le Caire.

Meers, D.; Favard-Meeks, C.

1995 Les dieux de l'Égypte. Paris.

MesKell, L.

1999 Archaeologies of social life. Age, sex, class et cetera in Ancient Egypt. Oxford.

Montet, P.

1946 La vie quotidienne en Égypte au temps des Ramsès (XIIIe - XIIe siècles avant J.-C.). Paris.

PARKINSON, R. B.

1995 "Homosexual" Desire and Middle Kingdom Literature, JEA 81: 57-76.

1998 The tale of Sinuhe and other ancient Egyptian poems 1940-1640 BC. Oxford.

2002 Poetry and culture in Middle Kingdom Egypt. A dark side to perfection. London.

[ 150 ] Parra Ortiz, J. M.

2003 Gentes del valle del Nilo. La sociedad egipcia en la época faraónica. Madrid.
2006 Le sexe aux temps des pharaons. Bordeaux.

QuiRKe, S.

1992 Ancient Egyptian Religion. London.

REDFORD, $\mathrm{S}$.

2002 The Harem Conspiracy. The Murder of Ramesses III. Dekalb.

RICHARD, J. E.

2002 Text and context in Late Old Kingdom Egypt: the archaeology and historiography of Weni the Elder, JARCE 39: 75-102.

SimPSON, W. K. (ED.)

2003 The literature of ancient Egypt. An anthology of stories, instructions, stelae, autobiographies and poetry. Cairo.

STRUDWICK, N.

2005 Texts from the pyramid age. Atlanta.

Te Velde, H.

1977 Seth, God of Confusion. A Study of His Role in Egyptian Mythology and Religion. Leiden.

VERNUS, P.

1993 Affaires et scandales sous les Ramsès. La crise des valeurs dans l'Égypte du Nouvel Empire. Paris.

Wente, E. F.

1990 Letters from Ancient Egypt. Atlanta.

WILLIAMS, R. J.

1972 Scribal training in ancient Egypt, JAOS 92: 214-221. 


\section{Trabajos de Egiptología Papers on Ancient Egypt}

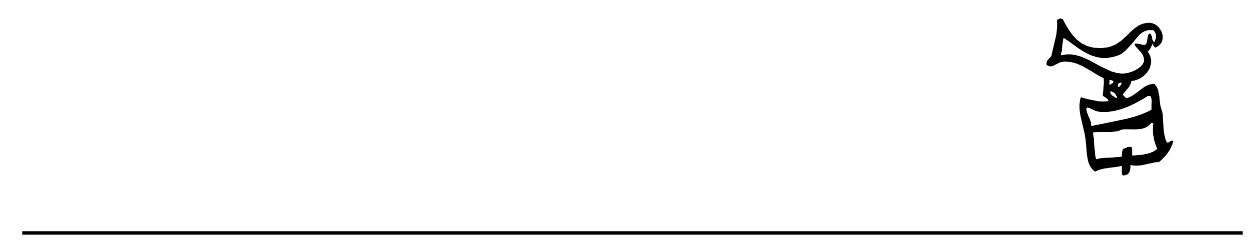

Número 5/2 2009 


\section{Actas \\ III Congreso Ibérico de Egiptología III Congresso Ibérico de Egiptologia}

Editores

Miguel Ángel Molinero Polo Covadonga Sevilla Cueva 


\title{
Editor
}

Miguel Ángel Molinero Polo

Universidad de La Laguna

\section{Consejo Editorial}

\author{
Antonio Pérez Largacha \\ Universidad de Castilla-La Mancha \\ José-R. Pérez-Accino \\ Birkbeck, Universidad de Londres \\ Covadonga Sevilla Cueva \\ Universidad Autónoma de Madrid
}

\section{Comité Científico}

Josep Cervelló i Autuori

Universitat Autònoma de Barcelona

$\mathrm{M}^{\mathrm{a}}$ José lópez Grande

Universidad Autónoma de Madrid

Josep Padró i Parcerisa

Universitat de Barcelona

$\mathrm{M}^{\mathrm{a}}$ Carmen Pérez Die

Museo Arqueológico Nacional, Madrid

Ester Pons Mellado

Museo Arqueológico Nacional, Madrid

José M. Serrano Delgado

Universidad de Sevilla

\section{Colaboradores Editoriales}

Linda Steynor

English editorial assistant

Hervé Mouriacoux

Assistant éditorial pour la langue française 
Trabajos de Egiptología está producida por Isfet. Egiptología e Historia c/ Blanco $1,2^{\circ}$

38400 Puerto de la Cruz

Tenerife-Islas Canarias

España

Maquetación: Proyecto Limón

(C) Autores de los artículos aparecidos

y Consejo Editorial de Trabajos de Egiptología - Papers on ancient Egypt

Depósito Legal: TF-2303-2009

ISSN: $1695-4750$

Imprime: Gráfica Los Majuelos, S.L.L.

imprenta@graficaslosmajuelos.com

Tfno.: 922311455 


\section{Comité Científico \\ III Congreso Ibérico de Egiptología III Congresso Ibérico de Egiptologia}

Miguel Á. Molinero Polo

Universidad de La Laguna

Presidente del Comité Organizador del III Congreso Ibérico de Egiptología

Miembro del Comité Organizador del I Encuentro de Egiptología

Josep Cervelló Autuori

Universitat Autònoma de Barcelona

Presidente del Comité Organizador del II Congreso Ibérico de Egiptologia

José Manuel Galán Allué

Consejo Superior de Investigaciones Cientificas

Director del Proyecto Djehuty, Luxor, Egipto

$\mathrm{M}^{\mathrm{a}}$ Helena Trindade Lopes

Universidad de Lisboa

Directora de la Misión Arqueológica Portuguesa en Menfis

Josep Padró i Parcerisa

Universitat de Barcelona

Director de la Misión Arqueológica de Oxirrinco

Antonio Pérez Largacha

Universidad de Castilla - La Mancha

Miembro del Comité Organizador del I Encuentro de Egiptología

José Ramón Pérez-Accino

Birkbeck College, University of London

Miembro del Comité Organizador del I Encuentro de Egiptología

$\mathrm{M}^{\mathrm{a}}$. Carmen Pérez Díe

Museo Arqueológico Nacional

Directora de la Misión Arqueológica Española en Heracleópolis Magna, Egipto

Covadonga Sevilla Cueva

Universidad Autónoma de Madrid

Miembro del Comité Organizador del I Encuentro de Egiptología 